\title{
Improving efficiency in the MSW collection and disposal service combining price cap and yardstick regulation: The Italian case
}

\author{
Authors \\ Massimo Beccarello, Giacomo Di Foggia \\ University of Milano-Bicocca
}

Citation

Di Foggia, G., Beccarello, M., 2018. Improving efficiency in the MSW collection and disposal service combining price cap and yardstick regulation: The Italian case. Waste Management. 79, 223-231. https://doi.org/10.1016/j.wasman.2018.07.040

Doi: https://doi.org/10.1016/i.wasman.2018.07.040

Article information

Preprint 


\section{Abstract}

The municipal solid waste collection and disposal service is a key element of the European strategy aimed at moving towards a circular economy. An efficient municipal solid waste collection and disposal is closely related to both lower waste tax and higher welfare of the interested population. In Italy, the lack of a centralized regulatory framework has determined heterogeneous performances of sector operators across the country. Firstly, we will be estimating the productive efficiency in different optimal territorial areas and secondly we will be forecasting the economic benefits that would arise under a new regulatory regime. Our approach combines the well-known yardstick competition and the price-cap mechanisms. Results suggest that if all territorial areas converged to the most efficient ones, a potential saving between $12 \%$ and $19 \%$ emerges, i.e., up to $€ 2 \mathrm{bn}$ savings out of $€ 10.05 \mathrm{bn}$ total tax revenue in 2015. 


\section{Introduction}

The municipal solid waste (MSW) collection and disposal service defines the waste collected by or on behalf of municipal authorities and disposed of through waste management systems. MSW consists mainly of waste generated by households, although it also includes similar waste from sources such as shops, offices and public institutions (Eurostat, 2017). Every local government provides a MSW collection and disposal service to its residents and although service levels, costs and the environmental impact vary deeply, it is arguably one of the most important municipal service (Hoornweg and Bhada-Tata, 2012). The MSW collection and disposal service has established itself as a pillar in the strategy for a more circular economy worldwide (Beccarello and Di Foggia, 2018). It thus follows from this that both the optimal territorial areas (OTAs) i.e. the area where integrated public services such as waste collection and disposal are organized and the financing system including the waste tax (WT) depend on economic and political factors too (Plata-Díaz et al., 2014). One may say that in Italy, the WT finances the full cost of the waste collection and disposal service since the proportion of the costs of collecting and disposing of MSW covered by WT is $98.9 \%$. In today's fast-paced business environment, waste management (including the collection and disposal service) is rapidly evolving towards a complex system of services, including planning, administrative, financial, engineering and legal functions. No wonder that it has a central role in environmental policies (EC, 2015). In this context, it is important to gain insight into the industry costs since they affect citizens via taxes and fees. Although the number of studies on the performance of MSW collection and disposal service has increased over the last decade, it remains quite distant from the literature of other infrastructure services (Simões and Marques, 2012). At the same time, the proper cost accounting has become a critical issue for waste disposal companies (Passarini et al., 2011), as performance measures have become 
prominent information for administrators, policymakers and regulators (Pérez-López et al., 2016). The latter shall progressively adopt or update the regulatory framework to maximize market efficiency and social well-being. In Italy, this transformation made it necessary to redesign the MSW management models previously carried out by municipalities. A wide-ranging debate has developed at an Italian institutional level on the need to confer regulatory powers to a specific sectoral authority. Similarly to the main network services (energy, telecommunications, water and transport) it would be necessary to develop a regulatory framework able to combine efficiency goals and, at the same time, to ensure greater homogeneity and convergence across the different OTAs. An adequate comparison of the costs of the service and their determinants represents the knowledge base for promoting an well planned service regulation model capable of promoting management efficiency throughout the national territory and thus guaranteeing social well-being. The past decade has seen the emergence of data on waste production and many studies have recently analyzed it; regarding costs, however, there is still little information available needed to better understand the empirical relationships important to policy making (Kinnaman, 2009). Our purpose is twofold. Firstly, we will be evaluating the level of efficiency achieved by the OTA and subsequently we will be estimating the economic benefits deriving from an innovative regulatory framework, based on an incentive method that combines the price cap mechanism and a parametric mechanism.

Our results confirm significant cost differences across different OTAs and suggest that if all OTAs converged to the most efficient ones the collectivity would save between $12 \%$ and $19 \%$ of current costs. The remainder of the paper is organized as follows. Firstly, we will be providing a brief overview of the Italian MSW context. Subsequently, the sources and the structure of the data will be listed in addition to the model used to estimate the average cost 
function of the service in order to fuel our analyses. Thereafter, the results of our estimates will be shown and through the parameters of cost and efficiency the potential cost savings deriving from an incentive regulation model will be assessed through a simulation performed over a five-year regulatory period. After discussing the implications of our simulation the conclusions will be drawn.

\section{Context}

Although MSW represents only about $10 \%$ of the total waste generated in the EU, countries which have developed efficient municipal waste collection and disposal services tend to perform better in overall waste management (EEA, 2016). EU waste policy and legislation occur within the context of a number of wider EU policies and programs and these initiatives include the seventh Environment Action Program, the Raw Materials Initiative and the Resource Efficiency Roadmap. Nevertheless, efforts to shift up the waste hierarchy have been on the go for longer in many countries, driven by earlier EU legislation such as the 1999 Landfill Directive. Together, these instruments establish a range of waste management targets and broader forward-looking goals (EEA, 2013). In Italy, the most significant advance in the sector dates back to the Legislative Decree 22/97, which promoted a model of aggregated management between several municipal administrations to improve economies of scale in the management of the service and to achieve two important objectives: minimizing the movement of waste and achieving self-sufficiency on the part of the municipal administrations involved. Self-sufficiency refers to each OTA that, as mentioned, defines the organizational perimeter of the waste management service. Nevertheless, the OTAs were designed in a deeply heterogeneous way along the country. It follows that, as we will see in the following parts of our work, the organizational differences determine dissimilar management efficiency standards across Italy. Indeed, in the field of MSW collection and disposal, many small 
businesses operate in an uncompetitive environment, with the frequent use of an in-house provision and an excessive contract length. The fragmentation of rules, often at municipal levels, has boosted different business models at local and regional level. Therefore, citizens pay different prices to service providers for the same or comparable kinds of services.

In addition to the two main points that deserve special attention, i.e., the efficiency level and a forward-looking regulatory mechanism, it should be noted that in the waste management sector competition levels both for the market and in the market are low. In fact, the direct inhouse award of MSW collection and disposal service prevails. Furthermore, a recent survey by the Italian Competition Authority reveals the duration of the awards tend to exceed the optimal period (AGCM, 2016).

Many studies have investigated the relationship between ownership form and performance (Lombrano, 2009). Indeed, the rising pressure in terms of cost efficiency of public services pushes governments to transfer part of those services to the private sector to decrease service costs (Jacobsen et al., 2013). Nonetheless, the conclusions on the effects of privatization are mixed (Simões et al., 2012). As far as we know, however, few studies analyze how a healthy regulation may affect performance and social well-being in the waste sector. A breakthrough in regulatory policy during the last decades has been the awareness that government's objectives for the utility industries can also take benefit from facilitating competition (Arrigo and Di Foggia, 2015). In this context, a good regulation can promote competition in certain industries by ensuring that market's power in natural-monopoly segments is not used abusively and by providing the correct incentives to business participants (Arnold et al., 2011). Among the forms of incentive regulation, the price cap and yardstick competition mechanisms emerge. The price cap is a method of regulating the prices of public services aimed at constraining the growth rate of prices or tariffs. On the one hand, an operator with high 
market power may abuse its dominant position through excessive pricing and on the other hand, unregulated firms maximize profits, leading to both deadweight losses and transfers of purchasing power from consumers to the firm. Both situations are costly to the regulator. To encourage companies to be efficient, the regulator can set a price cap that aims at tackling these problems; generally there is a trade-off between providing incentives and reducing excess profits (Cowan, 2002). In this sense, beside the price cap a regulatory agency can introduce the well-known concept of yardstick competition to deduce the costs of a firm by comparing such costs with those of other players which, although they are not direct competitors, operate in the same sector and under comparable market conditions (Shleifer, 1985). We have developed this idea in the Italian context in an effort to foresee potential benefits arising from effective regulation.

\section{Research objective, design \& method}

The emergence and evolution of literature on MSW services' cost and efficiency has been well documented and arguably represents one of the most thought-provoking topics in today's increasing international concern about public spending (Simões and Marques, 2012). Scholars have proposed many different approaches in an effort to shed light on the cost of the service. In general, the production function should consider the relationship between inputs and output produced (Berndt, 1991). More in detail, given the output $\mathrm{y}$ and some $\mathrm{x}_{\mathrm{i}}$ inputs with $\mathrm{i}=$ $1, \ldots, n$, a production function defines the maximum amount of $y$ depending on the combination of $x_{i}$ inputs with $i=1, \ldots, n$ net of exogenous contextual factors according to the level of technology A.

$$
y=f\left(x_{1}, \ldots, x_{n}, ; A\right)
$$

Provided that there are various ways to interpret eq. (1), from an economic point of view, basic assumptions must complement it, including profit and cost optimization assumptions. 
Since the level of output $y$ is predetermined (i.e. it is not a contemporaneous endogenous variable), prices of the $n$ inputs, $\mathrm{p}_{1}, \ldots . \mathrm{p}_{\mathrm{n}}$ are given and any rational operator shall minimize production costs, in this respect the relation in eq. (2) complements the production function.

$$
C=g\left(p_{1}, \ldots p_{n}, y ; A\right)
$$

Given that the relationship between inputs and output is not linear, a common approach is the Cobb-Douglas (Berndt, 1991). Our analysis stems from this methodology. Performance has most often been studied in terms of total cost and its determinants. Indeed, there are many ways to depict the functional form of total cost (TC) function as eq. (3) where $Q_{i}$ represents the quantity of MSW and TC is the total cost of collecting and disposing of MSW. The quadratic term takes into consideration a non-linear relationship between quantity and both marginal and average costs (Bohm et al., 2010).

$$
\ln \left(T C_{i}\right)=\alpha+\beta_{i} \ln Q_{i}+\beta_{2}\left(\ln Q_{i}\right)^{2}+\mu_{i}
$$

It goes without saying that besides companies' efficiency and service level, the cost of different waste disposal methods depends on the technology adopted and on the country's specific policy measures; for example, incineration costs are twice the costs of landfill (Bianchi, 2012). Given that performance, indicators shall be simple and reliable measures for monitoring services (Mendes et al., 2013), these indicators could gather many untapped potentials and serve stakeholders in strategic planning (Teixeira et al., 2014). The comparison between observed values and the maximal achievable optimal values is a streighforward way. We have estimated a frontier of efficiency according to well-known methods. Firstly, we have derived the cost function, after that the reference border was constructed. Value estimated by our model expresses the cost that the specific OTA would have in the service production if it operated according to the average industry standard. We have obtained the efficiency boundary by reclassifying the average cost values of OTAs from the most efficient (i.e., with 
the actual value compared to the lowest estimated value) to the least efficient ones. Subsequently, the calculated difference concerning the most efficient value (lower average cost) led to a comparative assessment regarding the relative efficiency level (Abbott and Cohen, 2009). Our efficiency assessment approach is based on commonly used parametric techniques rooted in the seventies (Kumbhakar et al., 2015), that use a standard production and cost function methodology. An alternative popular efficiency measurement technique is the data envelopment analysisis (Rogge and De Jaeger, 2013). Nevertheless, a potential advantage of our approach is that random variables can be accommodated. In this document we do not deal with the breakdown of technical and cost inefficiency; indeed, we focus on an operator's overall performance through measures such as the ratio of the potential cost over the observed cost as formalized in eq. (4) for convenience (Bauer, 1990; Fabbri, 1996).

$$
E f f_{i}=\frac{C_{i}=g\left(p_{1}, \ldots p_{n}, y ; A\right)}{C_{i}}=\frac{1}{e^{u_{i}}}
$$

We have assumed that a market regulation mechanism based on the dual combination of price cap and yardstick competition approaches would generate a convergence trend towards a higher performance in the medium-term. The potential cost saving depends on the assumptions made as per the benchmark. We have calculated such saving according to three scenarios that differ in the number of operators to include in the top performant cluster and in turn the level of efficiency. In the first scenario, our cost-efficiency target comprises only operators attaining a performance equal to or greater than the threshold fixed at $75 \%$ of the top performant operator. In the second scenario, the performance threshold corresponds to $85 \%$ of the top-ranked operator, while in the third scenario such threshold raises to $95 \%$ of the most efficient. 


\subsection{Data mining on municipalities}

We have collected and organized the data using the panel-data approach to get a meaningful estimate both in dynamic and comparative terms (Wooldridge, 2010). After proper data cleaning operations, aimed at eliminating the distorted values, we have aggregated the municipal information in 83 OTAs. Specifically, starting from the intitial 82 OTAs, we have excluded the Aeolian Islands and included three hypothetical OTAs based in the Lombardy Region, which instead availed itself of the derogation allowed by Legislative Decree 152/2006. The file dataset (strongly balanced) contained 249 total observations clusterd into $n=83$ OTA over $\mathrm{T}=3$ periods (2013-2015). Our analyses were based on multiple data sources. The detailed data on the quantities of waste collected comes from the MSW cadaster published by ISPRA and contains information on the type of waste collection, allowing the classification between DW and total MSW. More specifically, MSW ind corresponds to the sum of undifferentiated MSW, rubbish from street sweeping and other undifferentiated MSW, SDW indicates multi-material waste collection, and I identifies bulky waste for disposal. In the same way, the variable DW contains the organic fraction, packaging waste, multi-material collection, bulky waste for recovery, textiles, selective collection, paints and the like, WEEE and others. We can, therefore, define the following: $M S W=D W+M S W$ ind $+S D W+I$. The economic and financial information comes from the consultative balance sheet certificates of Italian municipalities contained in the AIDA PA database ( $86.5 \%$ of cases) and from primary sources such as WT financial plans (4.8\% of cases). For the remaining municipalities, we have estimated the amount by historical, territorial and dimensional values of the municipalities themselves weighted by the average values of the WT available in the literature (Garotta et al., 2016). As far as the orographic and morphological characteristics are concerned, we have 
used the municipal data published by ISTAT. Other information comes from the SPL observatory, INVITALIA's ATO monitor.

\subsection{The estimated model}

The WT per ton of MSW represents the variable with which we will evaluate the operational efficiency of the different OTAs, with the same service characteristics. We have represented the MSW collection and disposal service as a production activity with an environmental output. This activity requires the use of production factors that involve operating costs, the coverage of which determines the cost borne by the population. The dependent variable in our reference model is UWT, namely the log of $\left(\frac{\mathrm{WT}}{\mathrm{MSW}_{\mathrm{ton}}}\right)$ that stands for WT per ton of MSW. The independent variables that represent the main determinants of costs follows. POP and $\mathrm{KM}$ are the log of population and $\mathrm{Km}^{2}$ of the OTA respectively. The urbanization index URB is an indicator based on population density and contiguity. TRKM resumes the log of $\left(\frac{\mathrm{TR}}{\mathrm{Km}^{2}}\right)$ or the total revenue per $\mathrm{km} 2$ of the municipalities belonging to the OTA. PROLAB is the log of $\left(\frac{M S W_{t o n}}{L}\right)$ i.e. a measure of labor productivity as the ratio between the quantity of treated MSW and the staff employed in the MSW collection and disposal service. MWI is the log of $\left(\frac{\mathrm{MSW}_{\mathrm{ton}}}{\mathrm{Km}^{2}}\right)$ that represents the intensity of MSW production, i.e. tons of waste produced per square kilometer. Similarly DWI is the log of $\left(\frac{D_{\text {ton }}}{\mathrm{Km}^{2}}\right)$ and denotes the tons of differentiated waste (DW) produced per squared kilometer. UTA is the log of $\left(\frac{\mathrm{TA}}{\mathrm{MSW}_{\mathrm{ton}}}\right)$ and indicates the balance sheet value of tangible fixed assets per ton of MSW. Furthermore, we employ two additional variables in model 3 and model 4 , specifically ALT is the average altitude and LAT is an ordinal value for latitude tha may take three values: 1 stands for south and islas, 2 corresponds to the center and $3 \mathrm{I}$ the north of country. 
Table 1: descriptive statistics of variables

\subsubsection{The model}

The methodology used in this study is a regression-based analysis. The empirical evidence about cost drivers is heterogeneous with results and implications that often diverge regarding both operational and policy implications. From the premise about data characteristics it is possible to define a multiple regression on $\mathrm{i}=1 ; \ldots ., \mathrm{N}$ observations in $\mathrm{t}=1 ; \ldots ; \mathrm{T}$.

$$
y_{i t}=\propto+\beta_{1} x_{i t} \ldots+\beta_{k} x_{i t k}+a_{i}+u_{i t}
$$

The estimation of the determinants of the cost function served to infer on the relative efficiency of the managing entities through a parametric approach (Cambini et al., 2016). Since we did not have direct observations on the cost structure, quantitative information on the main factors of service production was approximated through variables. Production costs are influenced by the interaction between different factors, both exogenous such as population, the productive and economic structure of a given territory, and endogenous to the organizational model of the MSW management service, including technological choices, control of companies operating in the sector. Factors which literature identifies as cost drivers include: characteristics of the population, characteristics of the territory, characteristics of the productive and economic system, characteristics of the MSW, characteristics of service(Garotta et al., 2016; Greco et al., 2015; Guerrini et al., 2017; Mincarini, 2017). Starting from previous literature and our hyphoteses we estimated the eq. (6). 
(6) $\log \left(\frac{\mathrm{WT}}{\mathrm{MSW}_{\mathrm{ton}}}\right)_{\text {it }}$

$$
\begin{aligned}
& =\alpha+\beta_{1} \log (P O P)_{i t}+\beta_{2} \log (K M)_{i t}+\beta_{3} U R B_{i t}+\beta_{4} \log \left(\frac{\mathrm{TR}}{\mathrm{Km}^{2}}\right)_{i t} \\
& +\beta_{5} \log \left(\frac{M S W_{\text {ton }}}{L}\right)_{i t}+\beta_{6} \log \left(\frac{\mathrm{MSW}_{\mathrm{ton}}}{\mathrm{Km}^{2}}\right)_{i t}+\beta_{7}\left(\frac{\mathrm{DW}_{\mathrm{ton}}}{\mathrm{Km}^{2}}\right)_{i t} \\
& +\beta_{8} \log \left(\frac{\mathrm{TA}}{\mathrm{MSW}_{\text {ton }}}\right)_{i t}+u_{i t}
\end{aligned}
$$

From which eq. (7) can be carved according to the variable description above provided.

$$
\begin{aligned}
U W T=\alpha+ & \beta_{1} P O P+\beta_{2} K M+\beta_{3} U R B+\beta_{4} T R K M \\
& +\beta_{5} P R O L A B+\beta_{6} M W I+\beta_{7} D W I+\beta_{8} U T A \\
& +u
\end{aligned}
$$

\section{Results}

There are two main arguments that are worth an explanation: coefficients of our regression model and the comparison across OTAs. Model (1) in 
Table 2 represents the reference model as in eq. (7). Model (2) stems from the same regression but using MLE and one may observe that both models contain similar information. We added two additional models: Model 3 and Model 4 even if exogenous. Models 3 and 4 in table 2 contain two additional independent variables, namely ALT and LAT whose coefficients confirm a positive effect of the altitude on cost and that companies based in northern Italy show lower costs.

\section{Table 2: Econometric analysis}

The recent literature based on an analysis of the Italian context indicates positive economies of scale with regards to the total quantity of waste treated, but not regarding the separate collection (Greco et al., 2015), which, on the contrary, increase management costs. The results of our model go in the same direction and specifically the coefficients of the variables relative to the production per $\mathrm{km} 2$ of $\mathrm{MSW}\left(-0.857^{* * *}\right)$ and to the production per $\mathrm{km} 2$ of $\mathrm{DW}$ $\left(0.0707^{* * *}\right)$ show opposite signs as expected. In fact, while on the one hand the productive density of waste contributes to the optimization of the process and represents a positive factor for the objective of economies of scale, separate collection requires a more sophisticated organization and technological capacity. It is, therefore, not surprising that the cost of collecting undifferentiated waste is $45.3 \%$ of the cost of separate collection and this difference represents the higher costs of separate collection (CONAI, 2013). The variable's coefficient representing the value of tangible fixed assets for MSW is negative, as expected ($\left.0,0307^{* *}\right)$. The coefficient of the variable constructed as an indicator of labor productivity, being the ratio between waste and necessary personnel $\left(-0.0360^{* *}\right)$, reveals a significant inverse relationship between the number of employees per ton of MSW and the WT. It is a measure calculated by dividing the output produced by the input that corresponds to the personnel employed in the certainly restrictive hypothesis that the hours worked are 
homogeneous; this variable is influenced both by the organization of the service and by the choice of the combination of inputs employed. The two variables concerning the dimension of OTAs, i.e., population and surface, show opposite signs: positive in the first case and negative in the second. The first of the two, however, could be affected by the presence of urban areas (mainly provincial capitals) of medium or large size with higher costs than territories composed of small urban centers (Garotta et al., 2016). The degree of urbanization is also significant $\left(-0,189^{* *}\right)$ as the negative sign implies a decrease of WT per ton of MSW in OTAs with a higher degree of urbanization. While on the one hand population density can be a facilitating factor in economies of scale, on the other hand, it is noted that a higher population density can make collection services more expensive (Guerrini et al., 2017) for a number of factors including, for instance, greater technological and dimensional constraints on the vehicles used and the available time windows. Finally, the model also considers economic characteristics through a variable representing the total revenue per $\mathrm{Km} 2$ of the municipalities belonging to the OTA $\left(0,173^{* * *}\right)$, as it is correlated with the waste complexity. The coefficients listed above are functional to the estimation of the hypothetical cost (WT per ton of MSW) given the factors considered and represented by the variables in Table 1 . The estimated costs are useful both in defining the model and in assessing the efficiency of OTAs. In fact, these values allow the assessment of the ideal financial needs necessary to run the waste collection and disposal service i. e. how much this would cost in the different OTAs. Considering the comparison of the OTAs performance, Table 3 summarizes the main results by classifying them according to efficiency levels. The first column contains the list of OTAs under analysis. The second column shows the average costs in euros per ton ( $€ /$ ton) of MSW, while the third column shows the predicted $€$ /ton. The fourth column illustrates the measurement of the efficiency of each OTA compared to the one that was most efficient. The 
fifth column indicates the efficiency levels (of the fourth column) in terms of $€$ /ton. Each value can represent the cost delta of the OTA with respect to the most efficient. The sixth column shows the maximum potential savings of the specific OTA if it performed as the most efficient OTA.

\section{Table 3: comparable information}

Considering the result in terms of average incremental cost one may note that: 11 OTAs (13.25\%) show a level of inefficiency leading to an increase in the average $€ /$ ton of MSW between 0 and 50.32 OTAs (38.55\%) with an inefficiency level leading to an average cost of MSW between 50 and 100; 31 OTAs (37.35\%) have a level of inefficiency with an average $€$ /ton of MSW between 100 and 150;8 OTAs (9.64\%) have a level of inefficiency with an average value between 150 and $200 € /$ ton of MSW; and finally, in an OTA with an average cost of 200 $€ /$ ton of MSW higher than the benchmark. Table 2 also shows significant potential savings for citizens. The average cost reduction was $€ 33.5 \mathrm{~m}$, with a maximum value of $€ 376.37 \mathrm{~m}$ and a minimum value of $€ 0.45 \mathrm{~m}$. This empirical evidence suggests that there is significant potential for improvement which could be pursued through a centralized regulation model with incentive mechanisms.

\section{Discussion, implications and proposal}

We are aware that our analysis deals with problems of asymmetry on the specific cost structure of the regulated operators; however, through the introduction of an independent and centralized market regulation system it is possible to overcome these difficulties for consumers' benefit. Our results concur to bridge the information gap that is amplified in a sector characterized by few big utilities and a multitude of small and medium-sized enterprises both private and state-owned or controlled. The OTAs shall be functional to the creation of an efficient service and competition. The widespread regulation model should be replaced by a 
centralised regulatory model to overcome the prominent asymmetric information that characterizes this sector. We will develop this idea in more detail in the following section. Regulatory agencies can achieve both efficiency and convergence of performance goals through a well-designed dynamic market regulation mechanism. We propose an approach that combines the well-known price cap method (Rudnick and Donoso, 2000; Taylor and Weisman, 1996), already provided for by law 481/95, and a parametric method provided for by the literature on yardstick competition (Shleifer, 1985). Eq. (8) analytically represents the key elements of the price cap mechanism.

$$
p_{t}=p_{t-1}\left(1+\left(i p c_{t-1}-X\right)\right)
$$

The price $p_{t}$ periodically updates within a regulatory period considering the price of the previous year $\mathrm{p}_{\mathrm{t}-1}$. This occurs through an index that considers both the consumer price index at time $\mathrm{t}-1$, i.e. $\mathrm{CPI}_{\mathrm{t}-1}$, and the factor $\mathrm{X}$, namely the rate of change in productivity required by companies $\left(X_{t-1}-X_{t}\right)$ in the period considered (Shleifer, 1985). It follows that $p_{t} \leq C P I-X$. Based on the formula, market operators may annually re-evaluate the price. In order to increase the price at time $t$, operators shall improve productivity. However, the price cap mechanism requires all operators to target the same level of dynamic efficiency. Therefore, it does not guarantee a dynamic cost convergence and it does not promote mergers or acquisitions (de Vries and Verhagen, 2014). However, social equity requires that effective regulation of the sector be able to promote a homogeneous service burden nationwide for homogeneous services. The yardstick competition aims at providing incentives for regulated operators to rationalize costs (Fried et al., 2008; Rudnick and Donoso, 2000; Shleifer, 1985). The mechanism foresees rewards of each operator as a function of competitors' standards and its own performance (Vickers and Yarrow, 1988). In an industry the $n$ firms face the demand curve $Q(P)$ and an operator investing $z$ on cost-reduction achieve unit cost level $c(z)$, with $c(0)$ is $c_{0}$ 
and the lump-sum transfer to the operator is T (in case of lump-sum transfer existence). Under the mentioned condition profit $\pi$ is derived in Eq. (9).

$$
\pi=[P-c(z)] Q(P)-z+T
$$

Nevertheless, the function $\mathrm{c}(\mathrm{z})$ is unknown and this approach allows to replace the cost of individual operators with the industry average taking to the profit relation as in eq. (10).

$$
\pi=\left[\overline{c_{l}}-c(z)\right] Q \overline{\left(c_{l}\right)}-z_{i}+\overline{z_{l}}
$$

To simulate the effect we have introduced three assumptions valid for the first regulatory period: the number of options available i.e. option $A$ and option $B$, the productivity factor $X$ and the length of the regulatory period. In option A, the maximum prices that operators may apply link to standard costs with reference to a benchmark, while in option B the maximum prices that operators will be able to apply stem from historical costs and indexed using the price cap mechanism, for example by setting $X=5 \%$. The assumptions above take effect over a five-year regulatory period. The operators shall choose the option at the beginning of the regulatory period. Each year within the regulatory period, the two options determine a mechanism of self-selection: the most efficient operators opt for option $A$, while the least efficient ones go for option B. It is assumed, although not contemplated in this paper, that once the first regulatory period ends, the regulator shall update all the parametres, in order to set new goals. Indeed, in the second period the general efficiency level would be higher because of the improvement prompted by the first. Therefore, in the medium term this dual option approach will boost efficiency until all operators select the first option. Of course, the regulation of the service quality must complement the price regulation.

In order to support our statements, we have analyzed the implications of three scenarios of our proposal for sector regulation. As previously introduced in the first scenario, our costefficiency target comprises only OTAs attaining a performance equal or greater than the 
threshold fixed at $75 \%$ of the top performant one. In the second scenario, the performance threshold corresponds to $85 \%$, while in the third scenario, the most demanding, the target comprises those OTAs that perform at least at the $95 \%$ of the most efficienct one. This allows us to estimate the economic effects of the proposal in the three scenarios assuming a $5 \%$ coefficient of productivity recovery $X$, net of inflation for a 5-year regulatory period. Table 4 shows the potential savings estimated in the three scenarios. We base our estimates starting from the national WT revenue in 2015 i.e. about $€ 10.05 \mathrm{bn}$. The first section of Table 4 presents the potential savings under the first scenario. In the regulatory period of 5 years, total savings amounted to $€ 1.21 \mathrm{bn}$. Moreover, the number of OTAs that would opt in this period for the adoption of a price cap tariff update tend to decrease from 50 in the first period to 11 in the fifth period: this by virtue of both the increase in efficiency year after year and the marginal difference of OTAs' performance compared to the established threshold. Instead, the number of OTAs that find it more convenient to adopt the parametric method increase from 33 in the first period to 87 in the second period. In the second section of Table 4, we consider a higher level of efficiency with the $85 \%$ threshold. In this case, the estimated savings increase to $€ 1.68 \mathrm{bn}$ over the five years. The OTAs that in this case would opt for the price cap mechanism go from 70 in the first period to 29 in the fifth period. In the third section of Table 4 , we still increase the level of efficiency by setting the threshold to $95 \%$. The potential savings over the regulatory period reached $€ 1.96 \mathrm{bn}$. The number of OTAs that would opt for the price cap regulatory mechanism go from 79 in the first period to 56 at the end of the first regulatory period.

\section{Table 4: potential savings}

Our simulation confirms the expected results of the proposed regulatory mechanism. In the three scenarios, we have considered the progressive increase in the number of OTAs that each 
year opt for the parametric method. This means that the regulation mechanism favors a process of convergence towards the desired goals of the regulator. However, in determining the level of parametric efficiency, the regulator must consider the different technological capacities across OTAs and the related plant costs. If operators are conditioned (also for contractual reasons with local authorities) by rigid technology, the regulator will be able to use a less binding benchmark by replicating the mechanism for a second regulatory period to obtain greater convergence over a wider period. Alternatively, the regulator of the next regulatory period could re-estimate the cost parameters and update the efficiency levels to the new sector average and so forth until a satisfactory level is achieved with the resulting positive externalities. To complete our analysis, we have highlighted the potential savings if all regulated operators performed at the level of the most efficient ones chosen in the three scenarios. If all operators operated at the level of efficiency equal to that of the first scenario, savings would reach $€ 2.053 \mathrm{bn}$. If all OTAs were operating at the level of efficiency equal to that of the second scenario, savings would reach $€ 2.337 \mathrm{bn}$, whereas if all OTAs were operating at an efficiency level equal to that of the third scenario, savings would add up to $€ 2.616 \mathrm{bn}$.

\section{Conclusion}

Given the waste collection and disposal service's performance heterogeneity, the need to understand the determinants of such differences is more timely than ever for making people better off. An efficient service is also a core pillar in moving towards a circular economy. Firstly, we have assessed the costs of collection and disposal of MSW and considered some determinants of the cost structure. We then have analyzed the level of efficiency of the sector and verified the differences in performance across different OTAs. Data confirms that the efficiency level diverges significantly. Building on that we have highlighted a potential cost saving achievable through an innovative regulation. We have proposed a regulatory 
mechanism based on the use of the parametric method known as yardstick competition and price cap mechanism. Our approach fosters a process of convergence towards the predefined and desirable efficiency levels. The results of our simulation have shown a potential saving between $12 \%$ and $19 \%$ as compared with the current figure. We have obtained accurate results demonstrating that the efficiency differential among best and worst cases is unsustainable in the long term. The findings might be representative of a typical situation of service delivery. Moreover, it shall be noted that the considered WT is charged to citizens, although regarding the assimilation of industrial waste to urban waste one of the main issues is that the WT is also charged to the system of business activities, even if in some cases the service is not provided and the related costs are not borne. This could have a significant impact on the average cost of collection and disposal service. In view of the fact that the European Commission has adopted an ambitious plan to make the transition to a stronger and more circular economy this paper has serious policy implications. A more efficienct MSW collection and disposal service would help to create the confidence required to justify the investment needed to capacity building that is a social, environmental and economic priority. Future studies on the current topic, espectially in a internationally comparable manner, are therefore suggested in order to pave the way for a faster transition towards a circular economy. 


\section{References}

Abbott, M., Cohen, B., 2009. Productivity and efficiency in the water industry. Util. Policy 17, 233-244. https://doi.org/10.1016/j.jup.2009.05.001

AGCM, 2016. IC49 - Indagine conoscitiva sul mercato dei rifiuti urbani: meno discariche più raccolta differenziata [In-depth investigation into MSW]. Roma.

Arnold, J., Nicoletti, G., Scarpetta, S., 2011. Regulation, resource reallocation and productivity growth. EIB Pap. 16, 90-115.

Arrigo, U., Di Foggia, G., 2015. The scope of public organisations with productive functions: insights from the inefficiency of Italian local public transport. Eur. J. Gov. Econ. 4, 134154.

Bauer, P.W., 1990. Recent developments in the econometric estimation of frontiers. J. Econom. 46, 39-56. https://doi.org/10.1016/0304-4076(90)90046-V

Beccarello, M., Di Foggia, G., 2018. Moving towards a circular economy: economic impacts of higher material recycling targets. Mater. Today Proc. 5, 531-543. https://doi.org/10.1016/j.matpr.2017.11.115

Berndt, E.R., 1991. The practice of econometrics: classic and contemporary. Eddison-Wesley. Bianchi, D., 2012. Eco-efficient recycling. The Italian recycling industry between globalization and the crisis challenges.

Bohm, R.A., Folz, D.H., Kinnaman, T.C., Podolsky, M.J., 2010. The costs of municipal waste and recycling programs. Resour. Conserv. Recycl. 54, 864-871. https://doi.org/10.1016/j.resconrec.2010.01.005

Cambini, C., Meletiou, A., Bompard, E., Masera, M., 2016. Market and regulatory factors influencing smart-grid investment in Europe: Evidence from pilot projects and implications for reform. Util. Policy 40, 36-47. https://doi.org/10.1016/j.jup.2016.03.003 
CONAI, 2013. Indagine sui costi delle raccolte differenziate in Italia. Milano.

Cowan, S., 2002. Price cap regulation. Swedish Econ. Policy Rev. 9, 167-188.

de Vries, H.J., Verhagen, W.P., 2014. Impact of changes in regulatory performance standards on innovation: A case of energy performance standards for newly-built houses. Technovation 48-49, 56-68. https://doi.org/10.1016/j.technovation.2016.01.008

EC, 2015. Closing the loop - An EU action plan for the Circular Economy. European Commission, Bruxelles.

EEA, 2016. Municipal waste management across European countries See. https://doi.org/10.2800/475915

EEA, 2013. Managing municipal solid waste - a review of achievements in 32 European countries (No. 2). European Environment Agency, Copenhagen. https://doi.org/10.2800/71424

Eurostat, 2017. Municipal waste. Stat. Explain. your Guid. to Eur. Stat.

Fabbri, D., 1996. La Stima di frontiere di costo nel trasporto pubblico locale: una rassegna e un' applicazione [Estimating cost frontiers in local transport a review]. Dipartimento di Scienze Economiche, Università di Bologna, Bologna.

Fried, H.O., Lovell, C.A.K., Schmidt, S.S. (Eds.), 2008. The Measurement of Productive Efficiency and Productivity Growth. Oxford University Press, New York.

Garotta, V., Bordin, A., Caputo, A., De Donato, S., Russo, P., Viselli, R., Camerano, S., Dell'Aquila, C., 2016. Green book, 6th ed. UTILITATIS, Roma.

Greco, G., Allegrini, M., Del Lungo, C., Gori Savellini, P., Gabellini, L., 2015. Drivers of solid waste collection costs. Empirical evidence from Italy. J. Clean. Prod. 106, 364-371. https://doi.org/10.1016/j.jclepro.2014.07.011

Guerrini, A., Carvalho, P., Romano, G., Cunha Marques, R., Leardini, C., 2017. Assessing 
efficiency drivers in municipal solid waste collection services through a non-parametric method. J. Clean. Prod. 147, 431-441. https://doi.org/10.1016/j.jclepro.2017.01.079

Hoornweg, D., Bhada-Tata, P., 2012. What a waste. A Global Review of Solid Waste Management (No. 15), Urban Development knowledge. Washington.

Jacobsen, R., Buysse, J., Gellynck, X., 2013. Cost comparison between private and public collection of residual household waste: Multiple case studies in the Flemish region of Belgium. Waste Manag. 33, 3-11. https://doi.org/10.1016/j.wasman.2012.08.015

Kinnaman, T.C., 2009. The economics of municipal solid waste management. Waste Manag. 29, 2615-2617. https://doi.org/10.1016/j.wasman.2009.06.031

Kumbhakar, S.C., Wang, H.-J., Horncastle, A.P., 2015. A Practitioner's Guide to Stochastic Frontier Analysis Using Stata. Cambridge University Press.

Lombrano, A., 2009. Cost efficiency in the management of solid urban waste. Resour. Conserv. Recycl. 53, 601-611. https://doi.org/10.1016/J.RESCONREC.2009.04.017

Mendes, P., Santos, A.C., Nunes, L.M., Teixeira, M.R., 2013. Evaluating municipal solid waste management performance in regions with strong seasonal variability. Ecol. Indic. 30, 170-177. https://doi.org/10.1016/J.ECOLIND.2013.02.017

Mincarini, M., 2017. Valutazione dei costi di gestione del servizio di igiene urbana in Italia elaborazioni delle dichiarazioni MUD., in: Laraia, R. (Ed.), Rapporto Rifiuti Urbani[ Urban Waste Report]. ISPRA, Ispra, pp. 191-219.

Passarini, F., Vassura, I., Monti, F., Morselli, L., Villani, B., 2011. Indicators of waste management efficiency related to different territorial conditions. Waste Manag. 31, 785792. https://doi.org/10.1016/j.wasman.2010.11.021

Pérez-López, G., Prior, D., Zafra-Gómez, J.L., Plata-Díaz, A.M., 2016. Cost efficiency in municipal solid waste service delivery. Alternative management forms in relation to local 
population size. Eur. J. Oper. Res. 255, 583-592. https://doi.org/10.1016/j.ejor.2016.05.034

Plata-Díaz, A.M., Zafra-Gómez, J.L., Pérez-López, G., López-Hernández, A.M., 2014. Alternative management structures for municipal waste collection services: The influence of economic and political factors. Waste Manag. 34, 1967-1976. https://doi.org/10.1016/j.wasman.2014.07.003

Rogge, N., De Jaeger, S., 2013. Measuring and explaining the cost efficiency of municipal solid waste collection and processing services. Omega 41, 653-664. https://doi.org/10.1016/J.OMEGA.2012.09.006

Rudnick, H., Donoso, J.A., 2000. Integration of price cap and yardstick competition schemes in electrical distribution regulation. IEEE Trans. Power Syst. 15, 1428-1433. https://doi.org/10.1109/59.898123

Shleifer, A., 1985. A Theory of Yardstick Competition. RAND J. Econ. 16, 319-237.

Simões, P., Cruz, N.F., Marques, R.C., 2012. The performance of private partners in the waste sector. J. Clean. Prod. 29-30, 214-221. https://doi.org/10.1016/j.jclepro.2012.01.027

Simões, P., Marques, R.C., 2012. On the economic performance of the waste sector. A literature review. J. Environ. Manage. 106, 40-47. https://doi.org/10.1016/j.jenvman.2012.04.005

Taylor, L.D., Weisman, D.L., 1996. A Note on Price Cap Regulation and Competition. Rev. Ind. Organ. 11, 459-471.

Teixeira, C.A., Avelino, C., Ferreira, F., Bentes, I., 2014. Statistical analysis in MSW collection performance assessment. Waste Manag. 34, 1584-1594. https://doi.org/10.1016/j.wasman.2014.04.007

Vickers, J., Yarrow, G.K., 1988. Privatization: An Economic Analysis. MIT. 
Wooldridge, J.M., 2010. Econometric analysis of cross section and panel data, 2nd ed. MIT, Cambridge. 


\section{Annex 1}

Annex 1: Additional descriptive statistics

\begin{tabular}{|c|c|c|c|c|c|c|c|}
\hline Variable & & Mean & Std, Dev, & Min & Max & Obse & vations \\
\hline UWT & overall & 5.801 & 0.174 & 5.378 & 6.345 & $N=$ & 249 \\
\hline & between & & 0.160 & 5.482 & 6.310 & $\mathrm{n}=$ & 83 \\
\hline & within & & 0.068 & 5.446 & 6.214 & $\mathrm{~T}=$ & 3 \\
\hline POP & overall & 13.028 & 0.912 & 11.367 & 15.535 & $N=$ & 249 \\
\hline & between & & 0.916 & 11.372 & 15.532 & $\mathrm{n}=$ & 83 \\
\hline & within & & 0.003 & 13.019 & 13.036 & $\mathrm{~T}=$ & 3 \\
\hline KM2 & overall & 7.742 & 0.951 & 5.102 & 10.089 & $N=$ & 249 \\
\hline & between & & 0.955 & 5.102 & 10.089 & $\mathrm{n}=$ & 83 \\
\hline & within & & 0.00 & 7.742 & 7.742 & $T=$ & 3 \\
\hline URB & overall & 1.661 & 0.484 & 1.00 & 3 & $N=$ & 249 \\
\hline & between & & 0.486 & 1.00 & 3 & $\mathrm{n}=$ & 83 \\
\hline & within & & 0.00 & 1.661 & 1.661 & $\mathrm{~T}=$ & 3 \\
\hline TRKM2 & overall & 12.564 & 0.930 & 11.069 & 16.939 & $N=$ & 249 \\
\hline & between & & 0.925 & 11.298 & 16.516 & $\mathrm{n}=$ & 83 \\
\hline & within & & 0.126 & 12.016 & 12.987 & $\mathrm{~T}=$ & 3 \\
\hline PROLAB & overall & 13.673 & 1.254 & 11.622 & 17.998 & $N=$ & 249 \\
\hline & between & & 1.214 & 11.747 & 17.728 & $\mathrm{n}=$ & 83 \\
\hline & within & & 0.331 & 12.457 & 15.434 & $\mathrm{~T}=$ & 3 \\
\hline MWI & overall & 4.489257 & 0.976 & 2.971 & 7.897 & $N=$ & 249 \\
\hline & between & & 0.979 & 2.984 & 7.887 & $\mathrm{n}=$ & 83 \\
\hline & within & & 0.034 & 4.263 & 4.725 & $T=$ & 3 \\
\hline
\end{tabular}




\begin{tabular}{lllllll}
\hline Variable & & Mean & Std, Dev, & Min & Max & Observations \\
\hline DSI & Overall & 3.3480 & 1.305 & 0.402 & 6.727 & $\mathrm{~N}=249$ \\
& Between & 1.305 & 0.592 & 6.665 & $\mathrm{n}=83$ \\
& & & & & & \\
& within & & 0.120 & 2.959 & 3.840 & $\mathrm{~T}=3$ \\
& & & & & & \\
\hline
\end{tabular}

Source: own elaboration 
Table 1: descriptive statistics of variables

\begin{tabular}{llllll}
\hline Variable & Obs & Mean & Std. Dev. & Min & Max \\
\hline UWT & 249 & 5.801 & 0.174 & 5.378 & 6.345 \\
POP & 249 & 13.028 & 0.912 & 11.367 & 15.535 \\
KM & 249 & 7.742 & 0.951 & 5.102 & 10.090 \\
URB & 249 & 1.661 & 0.484 & 1.000 & 3.000 \\
TRKM & 249 & 20.306 & 0.974 & 18.235 & 23.091 \\
PROLAB & 249 & 13.673 & 1.254 & 11.622 & 17.999 \\
MWI & 249 & 4.489 & 0.976 & 2.971 & 7.897 \\
DWI & 249 & 3.348 & 1.305 & 0.402 & 6.728 \\
UTA & 249 & 3.907 & 1.621 & -3.559 & 7.216 \\
ALT & 249 & 3.205 & 1.023 & 1.000 & 5.000 \\
LAT & 249 & 1.843 & 0.900 & 1.000 & 3.000 \\
\hline
\end{tabular}

Source: own elaboration 


\begin{tabular}{|c|c|c|c|c|}
\hline & $\begin{array}{l}\text { Model (1) } \\
\text { GLS } \\
\text { (reference) }\end{array}$ & $\begin{array}{l}\text { Model (2) } \\
\text { MLE }\end{array}$ & $\begin{array}{l}\text { Model (3) } \\
\text { GLS }\end{array}$ & $\begin{array}{l}\text { Model (4) } \\
\text { MLE_bis }\end{array}$ \\
\hline VARIABLES & UWT & UWT & UWT & UWT \\
\hline \multirow[t]{2}{*}{ POP } & $0.767 * * *$ & $0.762 * * *$ & $0.725 * * *$ & $0.719 * * *$ \\
\hline & $(0.101)$ & (0.103) & $(0.102)$ & (0.103) \\
\hline \multirow[t]{2}{*}{ KM } & $-0.772 * * *$ & $-0.766 * * *$ & $-0.727 * * *$ & $-0.720 * * *$ \\
\hline & (0.0999) & $(0.103)$ & $(0.101)$ & $(0.103)$ \\
\hline \multirow[t]{2}{*}{ URB } & $-0.189 * *$ & $-0.188 * *$ & $-0.243^{* *}$ & $-0.242 * *$ \\
\hline & $(0.0956)$ & (0.0933) & $(0.101)$ & (0.0979) \\
\hline \multirow[t]{2}{*}{ TRKM } & $0.173 * * *$ & $0.173 * * *$ & $0.170 * * *$ & $0.170 * * *$ \\
\hline & $(0.0260)$ & (0.0258) & (0.0270) & (0.0268) \\
\hline \multirow[t]{2}{*}{ PROLAB } & $-0.0306 * * *$ & $-0.0307 * * *$ & $-0.0316 * * *$ & $-0.0318 * * *$ \\
\hline & (0.00929) & (0.00919) & (0.00919) & (0.00903) \\
\hline \multirow[t]{2}{*}{ MWI } & $-0.857 * * *$ & $-0.851 * * *$ & $-0.830 * * *$ & $-0.823 * * *$ \\
\hline & $(0.0766)$ & $(0.0840)$ & $(0.0771)$ & $(0.0833)$ \\
\hline \multirow[t]{2}{*}{ DWI } & $0.0707 * * *$ & $0.0686 * * *$ & $0.0962 * * *$ & $0.0937 * * *$ \\
\hline & $(0.0194)$ & $(0.0228)$ & $(0.0223)$ & $(0.0250)$ \\
\hline \multirow[t]{2}{*}{ UTA } & $-0.0307 * * *$ & $-0.0306 * * *$ & $-0.0289 * * *$ & $-0.0289 * * *$ \\
\hline & $(0.00562)$ & $(0.00555)$ & $(0.00562)$ & $(0.00553)$ \\
\hline \multirow[t]{2}{*}{ ALT } & & & 0.0286 & 0.0288 \\
\hline & & & $(0.0223)$ & $(0.0215)$ \\
\hline \multirow[t]{2}{*}{ LAT } & & & $-0.0528 * *$ & $-0.0519 * *$ \\
\hline & & & $(0.0226)$ & $(0.0222)$ \\
\hline \multirow[t]{2}{*}{ Constant } & $4.079 * * *$ & $4.076^{* * *}$ & $4.211^{* * *}$ & $4.205^{* * *}$ \\
\hline & $(0.384)$ & $(0.375)$ & $(0.414)$ & $(0.404)$ \\
\hline Observations & 249 & 249 & 249 & 249 \\
\hline Number of id_ato & 83 & 83 & 83 & 83 \\
\hline $\mathrm{R}^{2}$ & 0.309 & & 0.348 & \\
\hline$\sigma_{-} \mathrm{u}$ & 0.128 & 0.138 & 0.126 & 0.135 \\
\hline$\sigma \_\varepsilon$ & 0.0511 & 0.0566 & 0.051 & 0.056 \\
\hline$\rho$ & 0.8626 & 0.858 & 0.859 & 0.854 \\
\hline
\end{tabular}

Source: own elaboration. Standard errors in parentheses, ${ }^{* * *} \mathrm{p}<0.01,{ }^{* *} \mathrm{p}<0.05,{ }^{*} \mathrm{p}<0.1 . \mathrm{R}^{2}$ overall. Panel data with random effects (Prob $>\chi^{2}=0.3607$ ) and GLS (Prob $>\chi^{2}=0.5732$ ) 
Table 3: comparable information

\begin{tabular}{|c|c|c|c|c|c|}
\hline ATO & $\begin{array}{l}\text { WT/MSW } \\
\text { (Observed) }\end{array}$ & $\begin{array}{l}\text { WT/MSW } \\
\text { (predicted) }\end{array}$ & Performance & $\begin{array}{l}\text { Additionan } € \\
\text { per } \mathrm{MSW}_{\text {ton }}\end{array}$ & $\begin{array}{l}\text { Potential } \\
\text { €mn } \\
\text { saving per } \\
\text { OTA }\end{array}$ \\
\hline Friuli Venezia G & 240.93 & 337.26 & 100 & 0.00 & 0.00 \\
\hline Vicenza & 259.09 & 356.52 & 98.77 & 4.40 & 1.18 \\
\hline Isernia & 249.82 & 331.05 & 95.97 & 13.33 & 0.45 \\
\hline Fermo & 260.87 & 341.64 & 95.08 & 16.81 & 1.34 \\
\hline Lomb N & 253.81 & 331.03 & 94.77 & 17.32 & 21.79 \\
\hline Campobasso 1 & 299.4 & 375.99 & 91.81 & 30.8 & 1.55 \\
\hline Verona Nord & 252.13 & 314.75 & 91.33 & 27.28 & 5.46 \\
\hline MI-BG-BS & 289.73 & 354.51 & 89.71 & 36.47 & 94.9 \\
\hline Macerata & 278.51 & 331.84 & 87.51 & 41.45 & 6.03 \\
\hline Verona Sud & 273.55 & 321.40 & 86.33 & 43.95 & 4.57 \\
\hline Lomb S & 258.84 & 301.96 & 85.72 & 43.13 & 32.4 \\
\hline Vibo Valentia & 310.91 & 360.77 & 85.26 & 53.18 & 3.33 \\
\hline Belluno & 306.16 & 354.79 & 85.15 & 52.7 & 4.30 \\
\hline Catanzaro & 314.94 & 363.00 & 84.68 & 55.62 & 8.65 \\
\hline P di Trento & 303.95 & 348.06 & 84.11 & 55.30 & 12.48 \\
\hline Caltanissetta P S & 280.85 & 319.62 & 83.57 & 52.51 & 3.12 \\
\hline Agrigento P O & 303.08 & 340.5 & 82.43 & 59.83 & 3.15 \\
\hline Crotone & 276.76 & 307.75 & 81.51 & 56.91 & 4.41 \\
\hline Salerno & 392.91 & 435.43 & 81.20 & 81.85 & 35.91 \\
\hline Ancona & 292.63 & 324.81 & 81.35 & 60.59 & 13.92 \\
\hline Cuneese & 281.86 & 308.07 & 79.95 & 61.78 & 16.44 \\
\hline Napoli 3 & 383.77 & 417.48 & 79.51 & 85.53 & 34.91 \\
\hline Cosenza & 343.20 & 372.29 & 79.25 & 77.25 & 22.26 \\
\hline Verona Città & 298.60 & 324.51 & 79.42 & 66.78 & 8.88 \\
\hline Ascoli Piceno & 287.01 & 307.24 & 78.02 & 67.52 & 7.52 \\
\hline P Bolzano & 311.45 & 331.99 & 77.63 & 74.28 & 17.74 \\
\hline Napoli 1 & 430.37 & 458.9 & 77.66 & 102.54 & 66.52 \\
\hline Destra Piave & 357.52 & 378.02 & 76.86 & 87.46 & 17.08 \\
\hline Valle d'Aosta & 254.28 & 267.53 & 76.39 & 63.16 & 4.58 \\
\hline Rovigo & 277.73 & 292.09 & 76.35 & 69.07 & 8.49 \\
\hline Frosinone & 354.02 & 370.33 & 75.84 & 89.47 & 15.84 \\
\hline NO-VE. BI. V C & 343.39 & 357.45 & 75.37 & 88.03 & 32.78 \\
\hline Benevento & 441.31 & 458.53 & 75.19 & 113.74 & 10.58 \\
\hline Bari & 282.00 & 289.21 & 73.93 & 75.40 & 44.96 \\
\hline Brenta & 340.54 & 352.91 & 74.94 & 88.42 & 20.72 \\
\hline Abruzzo & 345.64 & 355.80 & 74.23 & 91.46 & 54.40 \\
\hline Campobasso 2 & 401.42 & 411.60 & 73.91 & 107.37 & 3.39 \\
\hline Padova Centro & 311.40 & 320.47 & 74.27 & 82.46 & 13.03 \\
\hline B A T & 293.22 & 299.60 & 73.57 & 79.19 & 14.16 \\
\hline Reggio Calabria & 337.27 & 343.71 & 73.31 & 91.72 & 21.12 \\
\hline Catania area M & 332.22 & 336.03 & 72.57 & 92.17 & 34.85 \\
\hline Rieti & 386.50 & 369.98 & 66.97 & 122.19 & 8.15 \\
\hline
\end{tabular}




\begin{tabular}{|c|c|c|c|c|c|}
\hline ATO & $\begin{array}{l}\text { WT/MSW ton } \\
\text { (Observed) }\end{array}$ & $\begin{array}{l}\text { WT/MSW } \text { ton } \text { (predicted) }\end{array}$ & Performance & $\begin{array}{l}\text { Additionan } € \\
\text { per } \mathrm{MSW}_{\text {ton }}\end{array}$ & $\begin{array}{l}\text { Potential } \\
€ m n \\
\text { saving per } \\
\text { OTA }\end{array}$ \\
\hline Pesaro e Urbino & 263.69 & 261.31 & 70.53 & 77.02 & 16.74 \\
\hline sinistra Piave & 395.02 & 390.37 & 70.25 & 116.15 & 12.20 \\
\hline Basilicata & 390.52 & 384.05 & 69.75 & 116.16 & 23.08 \\
\hline Latina & 300.61 & 294.66 & 69.42 & 90.11 & 26.96 \\
\hline Viterbo & 329.98 & 323.58 & 69.46 & 98.82 & 13.12 \\
\hline Astigiano e Ales. & 376.64 & 368.02 & 69.09 & 113.74 & 32.54 \\
\hline Torinese & 371.50 & 358.60 & 67.84 & 115.33 & 119.82 \\
\hline Messina area M & 375.86 & 361.06 & 67.34 & 117.92 & 25.24 \\
\hline Padova Sud & 315.09 & 301.46 & 66.92 & 99.73 & 11.01 \\
\hline Avellino & 451.24 & 430.22 & 66.55 & 143.89 & 20.87 \\
\hline Messina P & 370.61 & 352.93 & 66.43 & 118.48 & 7.82 \\
\hline Enna & 338.18 & 320.24 & 65.83 & 109.41 & 6.90 \\
\hline Napoli 2 & 404.79 & 374.83 & 63.44 & 137.02 & 44.63 \\
\hline Trapani P N & 342.74 & 317.74 & 63.57 & 115.75 & 17.42 \\
\hline Genova & 367.23 & 339.77 & 63.36 & 124.50 & 56.14 \\
\hline Caserta & 383.97 & 354.36 & 63.08 & 130.82 & 55.74 \\
\hline Emilia Romagna & 266.70 & 245.96 & 63.01 & 90.98 & 253.43 \\
\hline Savona & 304.64 & 279.43 & 62.42 & 105.02 & 18.41 \\
\hline Ragusa & 362.98 & 333.48 & 62.59 & 124.75 & 17.08 \\
\hline Brindisi & 357.58 & 327.07 & 62.11 & 123.93 & 22.73 \\
\hline Foggia & 351.42 & 319.95 & 61.60 & 122.85 & 33.00 \\
\hline Trapani P S & 323.42 & 294.34 & 61.56 & 113.15 & 7.01 \\
\hline Lecce & 345.85 & 314.40 & 61.43 & 121.25 & 46.09 \\
\hline Umbria & 349.08 & 312.42 & 59.70 & 125.89 & 58.90 \\
\hline Catania P S & 371.10 & 331.99 & 59.66 & 133.94 & 6.84 \\
\hline Toscana Centro & 322.41 & 286.45 & 58.88 & 117.78 & 108.25 \\
\hline Palermo area M & 384.66 & 337.00 & 57.30 & 143.91 & 65.33 \\
\hline Palermo P O & 441.51 & 381.18 & 55.61 & 169.20 & 8.88 \\
\hline Sardegna & 377.65 & 328.49 & 56.48 & 142.98 & 104.02 \\
\hline Roma & 406.26 & 349.80 & 55.30 & 156.37 & 376.37 \\
\hline Toscana Costa & 339.42 & 285.23 & 52.44 & 135.66 & 106.31 \\
\hline Agrigento P E & 350.81 & 289.89 & 50.43 & 143.71 & 22.28 \\
\hline Taranto & 310.98 & 250.77 & 47.43 & 131.84 & 38.70 \\
\hline Caltanissetta P N & 306.46 & 245.97 & 46.85 & 130.74 & 8.27 \\
\hline Siracusa & 349.61 & 276.30 & 44.91 & 152.22 & 29.16 \\
\hline Catania P N & 386.41 & 301.79 & 43.40 & 170.81 & 17.09 \\
\hline La Spezia & 379.71 & 295.84 & 43.09 & 168.37 & 20.49 \\
\hline Imperia & 370.70 & 287.81 & 42.64 & 165.09 & 21.65 \\
\hline Venezia & 347.99 & 270.00 & 42.55 & 155.10 & 75.44 \\
\hline Toscana S & 342.02 & 261.98 & 40.89 & 154.87 & 74.68 \\
\hline Palermo P E & 550.47 & 404.16 & 35.24 & 261.75 & 12.15 \\
\hline
\end{tabular}

Source: own elaboration 
Table 4: Potential savings

\begin{tabular}{|c|c|c|c|c|c|c|c|}
\hline Threshold & OTAs per option & $\mathrm{T}_{1}$ & $\mathrm{~T}_{2}$ & $\mathrm{~T}_{3}$ & $\mathrm{~T}_{4}$ & $\mathrm{~T}_{5}$ & $\begin{array}{c}\text { Total saving } \\
\text { (€bn) }\end{array}$ \\
\hline Potential savings & Opt for price cap & 50 & 40 & 29 & 16 & 11 & \multirow[b]{3}{*}{1.21} \\
\hline under hypothesis 1. & Opt for parametric & 33 & 43 & 54 & 67 & 72 & \\
\hline $\begin{array}{l}\text { a performance } \geq \\
75 \% \text { of the top } \\
\text { performant }\end{array}$ & $\begin{array}{l}\text { Annual } \\
(€ \mathrm{~m})\end{array}$ & 246 & 326 & 271 & 225 & 139 & \\
\hline Potential savings & Opt for price cap & 70 & 63 & 51 & 40 & 29 & \multirow{3}{*}{1.68} \\
\hline $\begin{array}{l}\text { under hypothesis } 1 . \\
\text { Operators attaining }\end{array}$ & Opt for Parametric & 13 & 20 & 32 & 43 & 54 & \\
\hline $\begin{array}{l}\text { a performance } \geq \\
85 \% \text { of the top } \\
\text { performant }\end{array}$ & $\begin{array}{l}\text { Annual } \\
\text { (€m) }\end{array}$ & 410 & 396 & 357 & 286 & 235 & \\
\hline Potential savings & Opt for price cap & 79 & 76 & 74 & 66 & 56 & \multirow[b]{3}{*}{1.96} \\
\hline under hypothesis 1. & Opt for Parametric & 4 & 7 & 9 & 17 & 27 & \\
\hline $\begin{array}{l}\text { a performance } \geq \\
95 \% \text { of the top } \\
\text { performant }\end{array}$ & $\begin{array}{l}\text { Annual } \\
(€ \mathrm{~m})\end{array}$ & 485 & 444 & 386 & 349 & 301 & \\
\hline
\end{tabular}

Source: own elaboration 